\title{
AUSCULTA CARDÍACA: BASES FISIOLÓGICAS - FISIOPATOLÓGICAS
}

\author{
CARDIAC AUSCULTATION: PHYSIOLOGICAL AND PHYSIOPATHOLOGICAL MECHANISMS
}

\section{Antônio Pazin-Filho ${ }^{1}$; André Schmidt² \& Benedito Carlos Maciel ${ }^{2}$}

\begin{abstract}
${ }^{1}$ Médico Assistente. ${ }^{2}$ Docentes da Disciplina de Cardiologia do Departamento de Clinica Médica. Faculdade de Medicina de Ribeirão Preto da Universidade de São Paulo.

Correspondência: Prof. Dr. Benedito Carlos Maciel. Departamento de Clínica Médica. Faculdade de Medicina de Ribeirão Preto - USPCampus Universitário - CEP 14048-900 -Ribeirão Preto - SP.
\end{abstract}

PAZIN FILHO A; SCHMIDT A \& MACIEL BC. Ausculta cardíaca: bases fisiológicas - fisiopatológicas. Medicina, Ribeirão Preto, 37: 208-226, jul./dez. 2004.

RESUMO: São revistos os mecanismos básicos, determinantes dos sons cardíacos, normais e anormais, com ênfase nas suas implicações para a ausculta cardíaca à beira do leito.

UNITERMOS: Auscultação Cardíaca. Ruídos Cardíacos.

\section{1- INTRODUÇÃO}

A revisão que se segue representa um esforço no sentido de abordar, de forma didática e resumida, os mecanismos que determinam a produção dos sons cardíacos, com ênfase nas suas implicações para a ausculta cardíaca à beira do leito, tendo, como público-alvo principal, o aluno de Medicina, que se inicia em semiologia. Procurou-se, ao longo do texto, priorizar os achados semiológicos de ausculta cardíaca com maior significado clínico, levando-se em consideração, principalmente, o seu caráter de prevalência e prognóstico. Procurou-se, também, na medida do possível, integrar conhecimentos de Fisiologia e Patologia aos achados semiológicos, no sentido de tornar o aprendizado mais fácil. Considerando-se que um dos objetivos básicos da Semiologia Médica é a caracterização de síndromes clínicas, o estudo, em separado, da ausculta cardíaca, destituída de outros achados de exame físico cardiovascular, oriundos da inspeção e palpação, bem como da história clínica, esta revisão deve ser encarada como um método auxiliar, devendo-se levar sempre em consideração os outros métodos citados.
Eles são valiosos, principalmente, na distinção entre achados auscultatórios que apresentem características similares, serão apontados no texto, embora não sejam este nosso objetivo principal. Em específico, no referente aos sopros cardíacos, para se atingir os objetivos acima, utilizou-se o recurso de explicar a gênese do sinal através da síndrome clínica prevalente, derivando, a posteriori, no texto, as mudanças para as demais doenças ou condições que apresentem o mesmo tipo de sopro.

O estupendo desenvolvimento tecnológico, que revolucionou a abordagem diagnóstica das doenças cardiovasculares nas duas últimas décadas, especialmente no que concerne aos métodos não invasivos, com destaque para a Doppler ecocardiografia, fez-se acompanhar de indesejável, provavelmente inconsciente, mas, infelizmente, progressiva desvalorização da técnica diagnóstica fundamental. As conseqüências desse fenômeno, no processo de formação das novas gerações de médicos, não poderiam ser mais deletérias, sem contar os enormes custos econômicos decorrentes da utilização desmedida de métodos diagnósticos sofisticados, sem sustentação em elementos clínicos 
consistentes. Parece, portanto, ser este um momento oportuno para se estimular a valorização da ausculta cardíaca como método de investigação de distúrbios do sistema cardiovascular.

\section{2- FASES DO CICLO CARDÍACO}

É fundamental, para a adequada compreensão dos mecanismos determinantes dos sons, gerados no coração e nas grandes artérias, que se tenha presente o conjunto de modificações hemodinâmicas, que ocorrem durante o ciclo cardíaco. Na Figura 1, tais eventos estão representados para o lado esquerdo da circulação, mas eles devem ocorrer, em uma outra escala de valores, embora com o mesmo padrão qualitativo, no lado direito. A excitação elétrica dos ventrículos, representada no eletrocardiograma de superfície pelo complexo QRS, inicia o processo de contração ventricular. Como decorrência imediata, a pressão intraventricular esquerda aumenta, supera a pressão atrial e determina o fechamento da valva mitral (Ponto 1$)$. O crescente aumento da pressão ventricular acaba por superar a pressão da aorta e, desse modo, determina a abertura da valva aórtica (Ponto 2). No intervalo entre o fechamento da valva mitral (Ponto 1) e a abertura da valva aórtica (Ponto 2), o ventrículo esquerdo apresenta um aumento da pressão intraventricular, sem que ocorra esvaziamento da cavidade. Esse intervalo de tempo é conhecido pela denominação de período de contração isovolumétrica. A abertura da valva aórtica delimita o início do período de ejeção ventricular, durante o qual ocorre, inicialmente, aumento, seguido de redução, concomitantes da pressão intraventricular e da aorta, que, durante essa fase, comportam-se como uma cavidade única. Tal período termina quando a pressão ventricular decrescente torna-se menor que a pressão da aorta (Ponto 3), determinando o fechamento da valva aórtica. Durante a ejeção ventricular, observa-se que o fluxo na aorta apresenta uma velocidade inicial rápida, atinge um pico de velocidade, e, posteriormente, em concomitância com a queda da pressão ventricular, man- tém um sentido anterógrado, mas com velocidades progressivamente menores, tendendo a zero ao final da sístole. O fluxo aórtico atinge um valor zero e até chega a ser transitoriamente retrógrado, quando a pressão ventricular fica menor que a pressão aórtica. $\mathrm{Pa}$ ralelamente, durante o período de ejeção, verifica-se uma redução progressiva, mas com velocidade variável, do volume ventricular, desde o seu valor máximo, ao final da diástole, até o seu valor mínimo, ao final da ejeção ventricular. Os períodos de contração isovolumétrica e de ejeção ventricular compõem a sístole ventricular. Após o fechamento da valva aórtica, ocorre, como decorrência do relaxamento ventricular, uma queda rápida e progressiva da pressão intraventricular até valores próximos de zero. Ao ficar menor que a pressão atrial, ocorrerá a abertura da valva mitral (Ponto 4), com o conseqüente início do período de enchimento ventricular. O intervalo de tempo entre o fechamento da valva aórtica e a abertura da valva mitral é denominado de período de relaxamento isovolumétrico, constituindo a primeira fase da diástole. Logo após a abertura da válvula mitral (Ponto 4), devido ao maior gradiente de pressão entre o átrio e o ventrículo, observa-se a segunda fase da diástole, a fase de enchimento rápido, seguida, devido à equalização de pressões entre as cavidades, da fase de enchimento lento ou diástase (terceira fase) e terminando pela fase de enchimento tardia, representada pela contração atrial (quarta fase). Este último componente é responsável, em corações normais, a aproximadamente $15-20 \%$ do volume de enchimento ventricular.

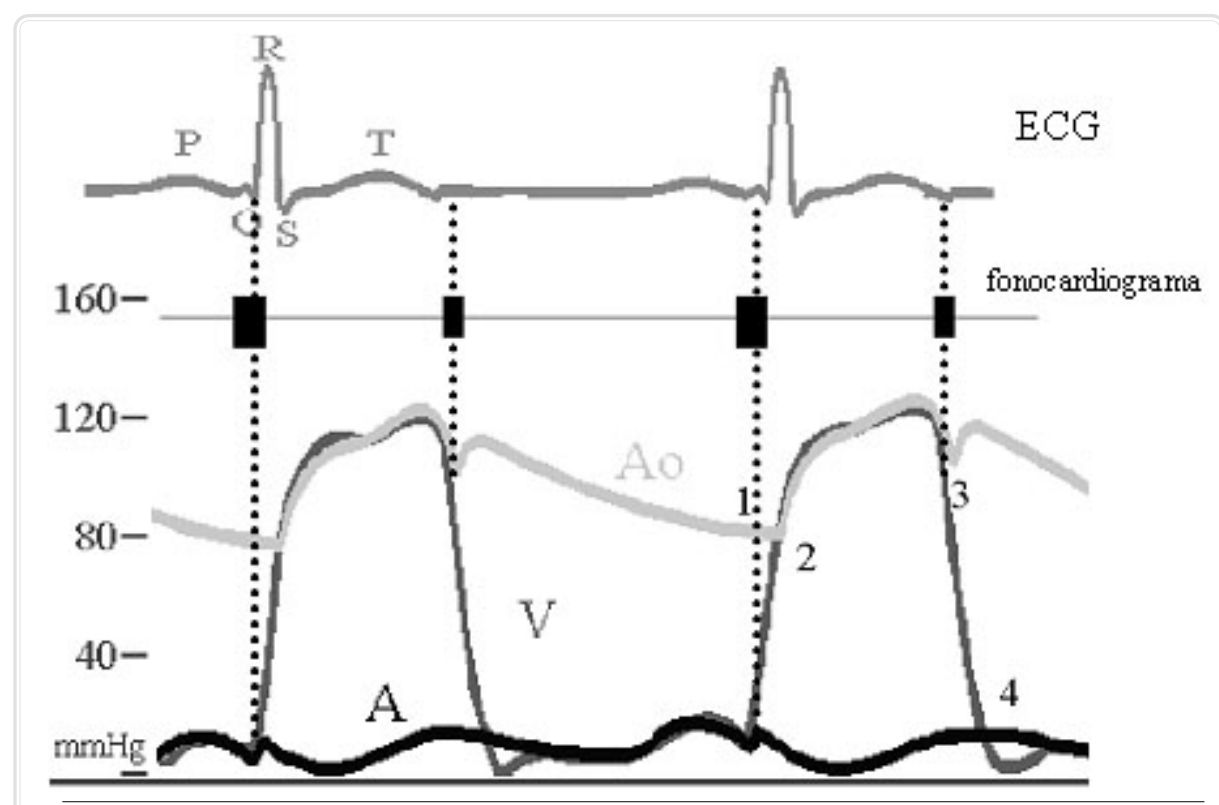

Figura 1: Esquematização do Ciclo Cardíaco. Vide texto para explicação. 


\section{3- PRINCÍPIOS BÁSICOS DE FÍSICA DAS ONDAS SONORAS}

As vibrações produzidas em estruturas cardíacas e vasculares, durante o ciclo cardíaco, propagamse até a superfície do corpo, obedecendo às leis da Física, que regem a condução de ondas através de meios de constituição diversa. Elas apresentam, na interface entre tais meios, refração e reflexão, com perda progressiva de energia ao longo do trajeto. Os ruídos e sopros produzidos no sistema cardiovascular correspondem a fenômenos sonoros que podem ser descritos de acordo com três características físicas fundamentais (Figura 2): intensidade (amplitude), freqüência (tonalidade) e qualidade (timbre). A intensidade de uma onda sonora diz respeito à quantidade de energia por unidade de área, perpendicular à direção de propagação, que compõe o referido som. A freqüência da onda sonora corresponde ao número de vibrações que ocorrem por unidade de tempo, sendo expressas, geralmente, em ciclos por segundo (cps) ou Hertz (Hz), o que equivale a 1 cps. A sensação auditiva, subjetiva, determinada pela freqüência das ondas sonoras é a tonalidade, que permite caracterizar os sons na dependência do predomínio dos componentes de baixa freqüência (graves) ou alta freqüência (agudos). A terceira característica fundamental é a qualidade (timbre) do som percebido pelo ouvido humano. Os sons produzidos no sistema cardiovascular são, na verdade, composições de diferentes freqüências sonoras. A análise dessas misturas complexas de freqüências diversas permite identificar freqüências que são múltiplas de uma freqüência fundamental (harmônicas) e dão ao som percebido pelo ouvido humano um timbre mais musical ou menos musical, na dependência do número de freqüências harmônicas que o compõe, o que permite caracterizar um sopro como musical ou um ruído como metálico.

\section{4- CARACTERÍSTICAS DA PERCEPÇÃO SO- NORA DO OUVIDO HUMANO}

O ouvido humano tem a capacidade de perceber vibrações sonoras, com freqüências variando entre 20 e $20.000 \mathrm{~Hz}$. As freqüências superiores a 20.000 $\mathrm{Hz}$ são chamadas de ultra-sônicas, enquanto as inferiores a $20 \mathrm{~Hz}$ são infra-sônicas. Estas, ainda que não sejam audíveis, podem ser percebidas pelo tato, como ocorre, por exemplo, na palpação do impulso apical. O limiar de audibilidade do ouvido humano varia em função da freqüência do som, sendo que os menores limiares ocorrem para sons de freqüência entre 1.000 e $2.000 \mathrm{~Hz}$, onde estão as freqüências da fala, verificando-se limiares progressivamente maiores para freqüências sonoras maiores e menores que as citadas. Isso significa que sons em tal faixa de freqüência serão percebidos com maior facilidade. Além disso, devese ter presente que a intensidade com que um determinado som é percebido (sensação subjetiva) não depende apenas da quantidade de energia que o compõe (amplitude), mas da inter-relação de amplitude com a tonalidade (freqüência) do som. Outro aspecto que merece destaque relaciona-se ao fato de que a maioria dos sons produzidos no sistema cardiovascular, que apresentam importância para o processo de ausculta cardíaca, situam-se em uma faixa de freqüência entre 20 e $500 \mathrm{~Hz}$, uma região de limiar da audibilidade relativamente elevado. A sensibilidade do ouvido humano também é influenciada pela intensidade de sons temporalmente próximos. Assim, um ruído muito intenso, em determinada posição do ciclo cardíaco, pode dificultar a percepção de outro som, menos intenso, em outra localização do ciclo cardíaco.

\section{5- PAPEL DO ESTETOSCÓPIO}

O estetoscópio capta e conduz até o aparelho auditivo as vibrações das estruturas cardíacas e vasculares que atingem a superfície do tórax. Além disso, ele tem a função de reduzir ou eliminar os ruídos ambientais durante o processo de ausculta cardíaca, ao

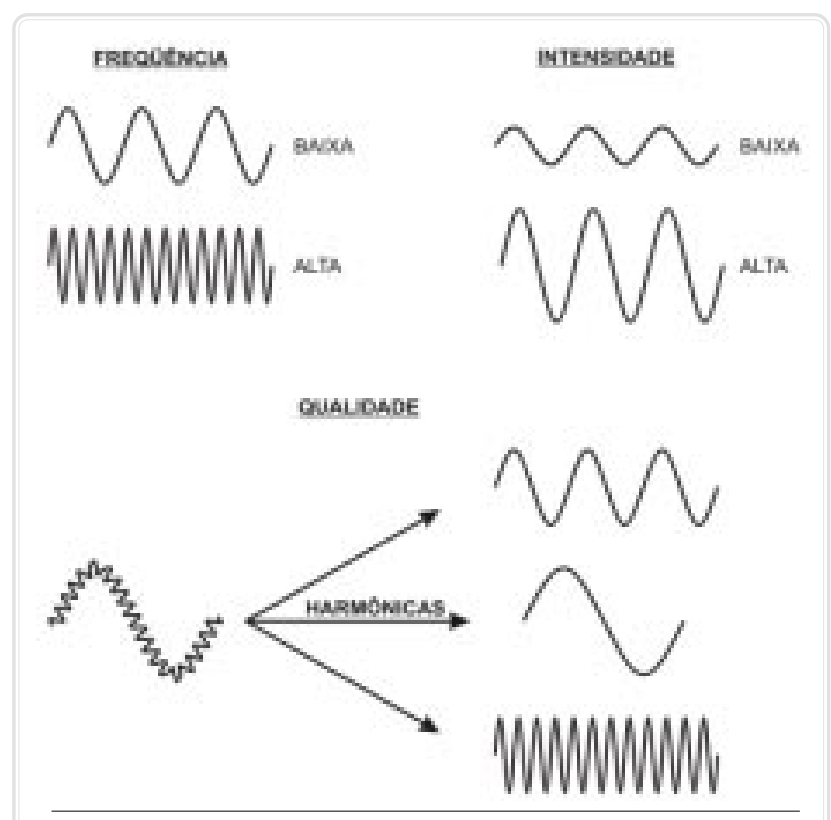

Figura 2: Características físicas das ondas sonoras. 
mesmo tempo em que, na dependência de características dos tubos que o compõem, pode até amplificar determinadas freqüências sonoras. Para obter melhor ausculta de sons de baixa freqüência $(30 \mathrm{a} 150 \mathrm{~Hz})$, o estetoscópio deve possuir uma campânula relativamente grande e pouco profunda, a ser aplicada suavemente sobre a superfície torácica. Os sons de alta freqüência são mais audíveis com o diafragma pressionado firmemente sobre o tórax, uma vez que a estrutura dele tem freqüência natural relativamente alta $\mathrm{e}$ filtra os sons de freqüência mais baixa. O diafragma pode, inclusive, amplificar determinados tipos de sopros que têm freqüência próxima de sua freqüência natural. Existem diversos tipos de aparelho e o conhecimento do aparelho em uso é muito importante para a adequada utilização. Alguns estetoscópios apresentam a campânula e a membrana separadas, opostas, e para se utilizar uma ou outra, a peça deve ser alternada. Outros apresentam campânula e membrana em uma única peça, e a seleção entre elas é obtida com a pressão exercida sobre a mesma.

De fundamental importância ainda, no estetoscópio, é a conformação de sua porção auricular. Elas devem estar ajustadas para respeitar a conformação anatômica básica do ouvido humano, ou seja, devem estar orientadas anteriormente.

\section{6- AUSCULTA CARDÍACA: TÉCNICA}

mesocárdio, a região paraesternal direita, o pescoço, a axila e a região infraclavicular e inter-escapulovertebral. Nesse sentido, é importante conhecer as direções naturais de propagação dos sons produzidos em diferentes valvas (Figura 3): os ruídos originários da valva mitral propagam-se freqüentemente em direção à axila, enquanto os sons da valva aórtica podem ser audíveis no pescoço ou ao longo da borda esternal esquerda; por outro lado, os ruídos dependentes das valvas situadas no lado direito da circulação tendem a se propagar pouco, mantendo-se mais restritos às áreas clássicas de ausculta os focos pulmonar e tricúspide. O decúbito lateral esquerdo (Figura 4), por outro lado, tende a amplificar a ausculta dos sons originários da valva mitral, enquanto a posição sentada tende a tornar mais audíveis os ruídos produzidos nas valvas semilunares.

A definição de uma seqüência lógica de ausculta cardíaca é um passo fundamental na aplicação de tal técnica propedêutica e, ainda que ela possa variar entre diferentes examinadores, ela deve conter todos os elementos relacionados no Quadro 1. Outro prérequisito básico consiste em tentar concentrar-se, individualmente, em cada um dos componentes da seqüência de avaliação auscultatória, analisando-se as características sonoras de seus elementos e sua variação com a respiração. Na seqüência proposta no Quadro 1, o passo inicial consiste em caracterizar o ritmo cardíaco do paciente em regular ou irregular,

A técnica de ausculta cardíaca, como ocorre com todo método de propedêutica clínica, deve, obrigatoriamente, envolver uma seqüência lógica e sistematizada de procedimentos direcionados no sentido de se obter o conjunto de informações fisiológicas que seja a mais abrangente possível. Assim, o paciente deve ser examinado em ambiente silencioso e em posição confortável. Não obstante as áreas clássicas de ausculta cardíaca (aórtica: segundo espaço intercostal direito; mitral: ápice; pulmonar: segundo espaço intercostal esquerdo; tricúspide: quarto espaço intercostal esquerdo, junto ao esterno) devam ser exploradas, rotineiramente, outras regiões também devem ser avaliadas, como o

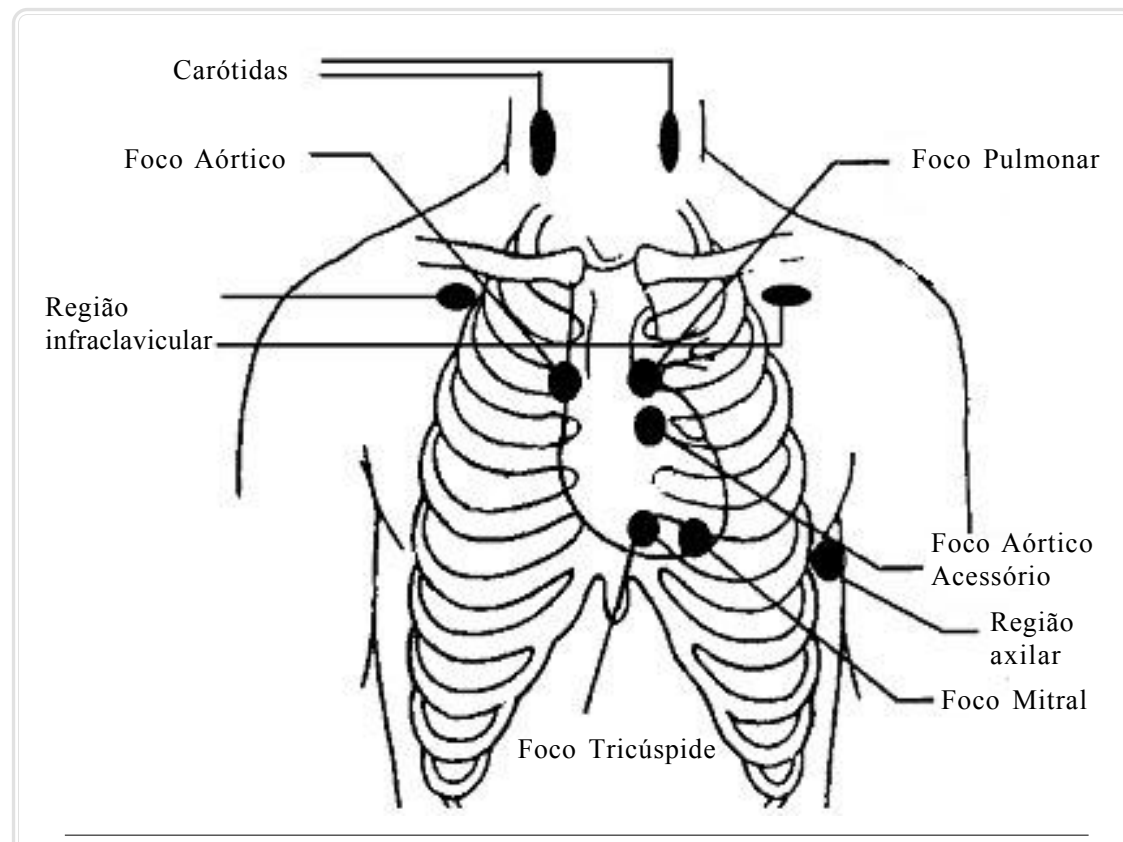

Figura 3: Áreas auscultatórias. 
bem como sua variação respiratória. Na segunda hipótese, é possível, eventualmente, identificar um padrão básico de regularidade sobre o qual, intermitentemente, se documentam batimentos isolados, precoces, como ocorre nas extrassistolias. Por outro lado, o ritmo cardíaco pode não apresentar qualquer padrão de regularidade, com os batimentos, ocorrendo em seqüência totalmente aleatória. Tal padrão é, às vezes, denominado de arritmia arrítmica e ocorre, por exemplo, na fibrilação atrial. Ainda que a ausculta cardíaca seja um método limitado para o diagnóstico preciso de arritmias cardíacas, é possível, mediante uma descrição detalhada do ritmo, reunir informações importantes para a caracterização de arritmias cardíacas. A seguir, avalia-se a freqüência cardíaca, que pode ser estimada pela média de batimentos em $15 \mathrm{ou}$ 30 seg quando o ritmo é regular, mas deverá considerar um tempo de 1 ou 2 min, para obtenção de um valor médio, quando houver arritmia cardíaca freqüente. A caracterização das bulhas cardíacas (primeira e segunda) é o passo seguinte, que inclui a identificação das mesmas, a avaliação de sua intensidade, a varia-

\section{Quadro 1 - Aus culta cardíaca: abordagem} siste matizada.

1. Caracterização do ritmo cardíaco

- Regular

- Irregular (arritmia respiratória, extrassistolia, arritmia arrítmica).

2. Freqüência cardíaca

3. Bulhas $\left(1^{\mathrm{a}}\right.$ e $\left.2^{\mathrm{a}}\right)$

- Intensidade

- Desdobramentos

4. Ruídos adicionais

- $3^{\mathrm{a}}$ e $4^{\mathrm{a}}$ bulhas

- Clicks, estalidos.

- Ruídos de próteses

5. Sopros cardíacos

- Fases do ciclo cardíaco

- Tipo

- Localização

- Duração

- Intensidade

- Tonalidade

- Timbre

- Irradiação

6. Atritos ção respiratória e a identificação de eventuais desdobramentos. A presença de ruídos adicionais deve ser pesquisada na seqüência, incluindo a identificação eventual de $3^{\mathrm{a}}$ e $4^{\mathrm{a}}$ bulhas, clicks ou estalidos e ruídos de próteses valvares ou de marca-passos. A pesquisa de sopros cardíacos é o passo seguinte, que deve incluir a caracterização da fase do ciclo, tipo, localização, intensidade, duração, tonalidade, timbre e irradiação. Finalmente, deve-se avaliar a existência ou não de atrito pericárdico.

\section{7- RUÍDOS CARDÍACOS BÁSICOS}

São ruídos transitórios, de curta duração, cuja propagação até a superfície do tórax depende do local de origem e da intensidade da vibração. Os sons que se originam do lado esquerdo do coração, geralmente, apresentam intensidade suficiente para serem audíveis em todo o precórdio, enquanto que aqueles gerados no lado direito, habitualmente, estão restritos a áreas limitadas da borda esternal esquerda, entre o segundo e quarto espaços intercostais.

\section{1- Primeira bulha cardíaca}

Mecanismos fisiológicos determinantes Ainda que alguma controvérsia tenha existido quanto aos mecanismos determinantes do primeiro ruído, parece ser consensual que dois componentes fundamentais têm maior importância na sua gênese: o primeiro é composto de vibrações intensas de alta freqüência, ocorre como conseqüência da tensão e desaceleração abrupta da valva mitral (M1) durante seu fechamento, que delimita o início da sístole; o segundo é, também, constituído de vibrações de alta freqüência, ocorre em média $30 \mathrm{~ms}$ depois do primeiro e depende da desaceleração súbita do sangue, determinada pela tensão a que a valva tricúspide (T1) é submetida durante seu fechamento. $\mathrm{O}$ fechamento das valvas atrioventriculares, assim, coloca em vibração os componentes valvares e do sangue, que dão origem ao primeiro ruído cardíaco. Dois outros componentes têm sido descritos como participantes da gênese do primeiro ruído cardíaco: um deles precede o componente mitral, é composto de vibrações de baixa freqüência e parece estar relacionado com o início da contração ventricular esquerda; o outro, acontece depois do componente tricúspide da primeira bulha e coincide com a aceleração do sangue dentro dos grandes vasos. Esses dois componentes não são audíveis à beira do leito, podendo apenas ser registrados pela fonocardiografia. $\mathrm{Na}$ prática clínica, como decorrência da proximidade 
temporal dos componentes mitral e tricúspide do primeiro ruído, nem sempre é possível distingui-los em condições normais, o que faz com que tal ruído, muitas vezes, seja percebido como um som único, de duração relativamente prolongada.

\section{2- Segunda bulha cardíaca}

Mecanismos fisiológicos determinantes As valvas semilunares, durante seu fechamento, são submetidas à tensão que determina uma abrupta desaceleração do sangue e do movimento valvar. As vibrações resultantes desse processo dão origem ao segundo ruído cardíaco. Ele é constituído por dois componentes temporalmente distintos: o primeiro depende do fechamento mais precoce da valva aórtica (A2) relativamente ao da valva pulmonar (P2), ao qual se associa o segundo componente. Na maioria dos indivíduos normais, percebe-se um ruído único durante a expiração, enquanto que, na inspiração, esses componentes são identificados separadamente, o que caracteriza o desdobramento fisiológico do segundo ruído cardíaco. Esse desdobramento depende, por um lado, e principalmente, de uma seqüência de eventos fisiológicos, que se inicia com a redução da pressão intratorácica, induzida pela inspiração, resultando em aumento do retorno venoso sistêmico, prolongamento do enchimento ventricular direito, e retardo no aparecimento do componente pulmonar da segunda bulha; por outro, ocorre durante inspiração, acúmulo de sangue em território pulmonar, com conseqüente redução do retorno venoso para o lado esquerdo do coração e da duração da sístole ventricular esquerda, resultando em aparecimento mais precoce do componente aórtico do segundo ruído. Mais recentemente, passou-se a considerar que o fator mais importante no atraso da ocorrência do componente pulmonar depende do aumento da capacitância pulmonar na inspiração e suas conseqüências sobre a dilatação do leito vascular pulmonar, e estaria menos relacionada às alterações do volume ventricular direito durante a respiração. A adequada avaliação dessa variação fisiológica requer a execução da ausculta durante respiração profunda e de baixa freqüência, sendo menos perceptível quando é realizada durante apnéia inspiratória ou expiratória. A magnitude de tal desdobramento reduz-se à medida que a idade dos indivíduos aumenta.

\section{3- Primeira e segunda bulhas, como marcado- res descritivos dos fenômenos auscultatórios}

O primeiro (B1) e segundo (B2) ruídos cardíacos delimitam os intervalos a partir dos quais todos os eventos observados na ausculta cardíaca são descritos. O início da sístole ventricular é clinicamente identificado pela primeira bulha, enquanto o segundo ruído marca o início da diástole ventricular. Assim, a identificação desses dois sons é elemento primordial do processo auscultatório. Em freqüências cardíacas, observadas habitualmente em condições basais de repouso, o intervalo sistólico é mais curto que o intervalo diastólico, mas a diferença torna-se menos perceptível à medida que a freqüência cardíaca se eleva. O primeiro ruído mostra-se mais intenso na região apical e porção inferior da borda esternal esquerda, enquanto a intensidade do segundo ruído tende a ser mais proeminente nos focos da base. A proximidade temporal entre a ocorrência da primeira bulha e o início do pulso carotídeo é outro elemento clínico que pode auxiliar a distinção entre os dois sons. A partir da identificação de $\mathrm{B} 1$ e de $\mathrm{B} 2$, todos os demais eventos auscultatórios podem ser, então, localizados no ciclo cardíaco. Os eventos sistólicos podem ser classificados como proto, meso ou telessistólicos, na dependência de ocorrerem na porção inicial, no meio ou ao final da sístole, enquanto os fenômenos diastólicos são caracterizados como proto, meso ou telediastólicos.

Observe novamente a Figura 1. No centro da figura, encontra-se um traçado de fonocardiograma, representando os dois ruídos cardíacos básicos. Podese observar, na figura, que o primeiro ruído (B1) é concomitante à elevação da pressão ventricular acima da pressão atrial (ponto1), momento em que a válvula mitral se fecha, enquanto o segundo ruído (B2) é concomitante à queda da pressão ventricular abaixo da pressão aórtica, momento em que a válvula aórtica se fecha (Ponto 3). No entanto, não se observa na figura nenhuma representação no fonocardiograma para os pontos 2 e 4, que representam o momento em que as válvulas aórtica e mitral se abrem, respectivamente. Pode-se observar que, nos pontos 1 e 3 , quando as válvulas se fecham, existe um gradiente de pressão significativo entre as câmaras que as válvulas delimitam. Assim, por exemplo, entre o átrio e o ventrículo esquerdos, no momento em que a válvula mitral se fecha (Ponto1), o gradiente é da ordem de $120 \mathrm{mmHg}$, enquanto que, no momento em que a válvula se abre (Ponto 4), o gradiente é da ordem de $5 \mathrm{mmHg}$. Do mesmo modo, entre a aorta e o ventrículo esquerdos, no momento em que a válvula aórtica se fecha (Ponto 3), o gradiente é da ordem de $80 \mathrm{mmHg}$, enquanto que, no momento em que ela se abre (Ponto 4), praticamente, não existe gradiente, pois as pressões da aorta e do ventrículo se elevam concomitantemente. 
Das observações anteriores pode-se depreender uma regra muito importante em ausculta cardíaca: a de que os ruídos cardíacos normais e anormais, bem como os sopros, estão relacionados à presença de um gradiente de pressão entre dois pontos. Caso tal gradiente não exista, não haverá tradução na forma de som. É claro que, como tudo em Medicina, em algumas ocasiões não se pode observar uma correlação direta entre a intensidade do som e o gradiente, mas, de maneira geral, essa regra traduz a base do entendimento da ausculta cardíaca.

\section{4- Variações da ausculta da primeira e segun- da bulhas cardíacas}

Intensidade - A avaliação da intensidade das bulhas obedece a critérios que padecem de grau significativo de subjetividade. É importante, no entanto, ao tentar caracterizar um ruído cardíaco como apresentando uma intensidade normal (normofonético), reduzida (hipofonético) ou aumentada (hiperfonético), ter presente a variação fisiológica da intensidade de bulhas nas diferentes regiões do precórdio, as características anatômicas (forma e espessura) do tórax e reconhecer a existência de fatores fisiológicos, que podem facilitar ou prejudicar a ausculta cardíaca. A intensidade do primeiro ruído cardíaco irá depender da interrrelação entre esses múltiplos fatores fisiológicos e aspectos da anatomia do tórax, determinantes da transmissão das vibrações sonoras. Tal intensidade mantém uma relação direta com a velocidade de elevação da pressão ventricular, e com a distância percorrida pelos folhetos da valva mitral desde o momento do início da contração ventricular até o fechamento valvar; por outro lado, uma relação inversa é verificada com o grau de rigidez dos folhetos valvares. Com base em tais elementos, é possível identificar um conjunto de situações fisiológicas, ou não, que determinam hipofonese ou hiperfonese da primeira bulha cardíaca (Quadro 2). Características anatômicas do tórax podem facilitar a ausculta da primeira bulha, como ocorre em pacientes com tórax pouco espesso, determinando, hiperfonese do ruído ou, em oposição, podem dificultar a propagação das vibrações, como documentado em indivíduos obesos e com doença pulmonar, obstrutiva, crônica ou, também, quando há interposição de estruturas entre o coração e o ouvido humano, como no derrame pericárdico e tamponamento cardíaco. Situações clínicas, nas quais se documenta um aumento do desempenho ventricular, decorrente de circulação hiperdinâmica, como no estado febril, hipertireoidismo, anemia ou durante exercício físico, observa-se o aumento da intensidade da primeira bulha. Pelo contrário, nos estados de baixo débito cardíaco (choque circulatório, miocardiopatias congestivas), a hipofonese pode ser identificada como resultado da depressão da função sistólica ventricular. Em pacientes com bloqueio completo do ramo esquerdo, o primeiro ruído pode se apresentar hipofonético, como conseqüência da menor velocidade de elevação da pressão ventricular, determinada pelo assincronismo da contração ventricular esquerda. O grau de abertura da valva mitral, no momento do início da contração ventricular, ou a distância a ser percorrida pelos folhetos valvares, até o fechamento valvar, explica a hiperfonese de B1, documentada na estenose mitral, no mixoma atrial esquerdo e, ainda, quando o intervalo P-R no eletrocardiograma é curto $(120 \mathrm{~ms})$. Esse mesmo mecanismo, determinando o posicionamento dos folhetos valvares, próximo da posição de fechamento, no momento da contração ventricular, é responsável pela observação de hipofonese de primeira bulha, na presença de intervalos P-R longos (200 - $500 \mathrm{~ms}$ ) e de insuficiência aórtica grave. Refere-se comumente à insuficiência mitral como uma condição clínica em que o primeiro ruído se apresenta freqüentemente hipofonético. No entanto, tal observação parece depender mais da influência de um sopro sistólico muito intenso sobre a capacidade de percepção da bulha. Muitas vezes, inclusive, pode-se documentar hiperfonese na ausculta da insuficiência mitral, provavelmente relacionada à extensão da excursão valvar até o fechamento. A posição dos folhetos valvares, no momento do início da contração ventricular, também determina a variação de intensidade da primeira bulha, observada na fibrilação atrial, quando se constata a relação das bulhas menos intensas com os intervalos $\mathrm{R}-\mathrm{R}$ mais prolongados, e vice-versa. O grau de rigidez dos folhetos valvares pode desempenhar papel determinante na redução da intensidade do primeiro ruído, tal como se documenta na estenose mitral calcificada. Por outro lado, valvas com prolapso valvar, associadas à degeneração mixomatosa, e folhetos amplos, tendem a dar origem a primeiro ruído hiperfonético.

A intensidade da segunda bulha cardíaca também depende de um conjunto variado de fatores, incluindo: os níveis de pressão arterial em território sistêmico ou pulmonar, a velocidade de variação da pressão arterial na diástole, o grau de fibrose e espessamento das valvas semilunares, a posição espacial relativa dos vasos da base do coração em relação à 
Quadro 2 - Variações da intensidade do primeiro ruído cardíaco.

\section{Mecanismo \\ Anatomia torácica \\ Velocidade de elevação da pressão ventricular}

Amplitude da excursão dos folhetos

Rigidez dos folhetos

\section{Hiperfonese}

Espessura diminuída do tórax

Estados hiperdinâmicos (febre, anemia, tireotoxicose, exercício).

Estenose mitral, mixoma atrial, P-R curto.

Valva mitral com degeneração mixomatosa e folhetos amplos

\section{Hipofonese}

Obesidade, enfisema pulmonar, tamponamento cardíaco.

Estado de baixo débito cardíaco (choque, miocardiopatia).Bloqueio de ramo esquerdo

P-R longo (200-500 ms) Insuficiência aórtica grave

Estenose mitral calcificada parede, bem como de fatores que facilitem, ou prejudiquem, a transmissão do som através da parede torácica. É importante lembrar, ao avaliar clinicamente a intensidade do segundo ruído, que o componente pulmonar tem sua ausculta mais restrita ao foco pulmonar, enquanto o componente aórtico tem uma distribuição auscultatória mais ampla. Portanto, hiperfonese ou hipofonese poderão ser documentadas, clinicamente, dependendo da ocorrência dos fatores mencionados (Quadro 3). Obviamente, os fatores anatômicos e aqueles dependentes da dinâmica circulatória, que influenciavam a intensidade do primeiro ruído, têm o mesmo papel no que diz respeito à segunda bulha. A presença de hipertensão arterial nos territórios sistêmico e pulmonar é determinante de, respectivamente, hiperfonese do componente aórtico e pulmonar do se- gundo ruído. Em contraposição, situações clínicas às quais se associam hipotensão nesses territórios, como ocorre nos estados de baixo débito cardíaco, estão associadas à hipofonese desse ruído. Tal mecanismo também está implicado na hipofonese de P2, documentada em cardiopatias congênitas, associadas a baixo fluxo pulmonar. Hiperfonese do segundo ruído também pode ser detectada, quando a aorta (A2) ou o tronco da artéria pulmonar (P2) estão mais próximos da parede torácica, como é o caso em dilatações desses vasos ou, por exemplo, na transposição das grandes artérias e tetralogia de Fallot. Uma redução seletiva da intensidade do componente aórtico ou do pulmonar pode também ser observada em conseqüência da rigidez e perda de mobilidade dos folhetos valvares, como verificado na estenose valvar aórtica ou pulmonar.

Quadro 3 - Variações da intensidade da segunda bulha.

\begin{tabular}{l|l|l}
\hline \multicolumn{1}{|c|}{ Mecanismo } & \multicolumn{1}{c|}{ Hiperfonese } & \multicolumn{1}{c}{ Hipofonese } \\
\hline Anatomia torácica & Espessura diminuída do tórax & $\begin{array}{l}\text { Obesidade, enfisema pulmonar, } \\
\text { tamponamento cardíaco. }\end{array}$ \\
\hline $\begin{array}{l}\text { Velocidade de redução da pressão } \\
\text { ventricular }\end{array}$ & $\begin{array}{l}\text { Estados hiperdinâmicos (febre, } \\
\text { anemia, tireotoxicose, exercício). }\end{array}$ & $\begin{array}{l}\text { Estados de baixo débito cardíaco } \\
\text { (choque, miocardiopatia). }\end{array}$ \\
\hline $\begin{array}{l}\text { Pressão arterial sistêmica/pulmonar } \\
\text { Hipertensão arterial sistêmica (A2); } \\
\text { hipertensão pulmonar. }\end{array}$ & Hipofluxo pulmonar (P2) \\
\hline $\begin{array}{l}\text { Relação espacial grandes } \\
\text { vasos/parede torácica }\end{array}$ & $\begin{array}{l}\text { Dilatação da aorta (A2) ou pulmonar } \\
\text { (P2), transposição grandes artérias, } \\
\text { (A2), Tetralogia de Fallot(A2). }\end{array}$ & \\
\hline Rigidez dos folhetos & & Estenose valvar, aórtica ou pulmonar
\end{tabular}


Do ponto de vista prático, em que pesem as considerações já expostas, é de fundamental importância a comparação da fonese das bulhas entre focos com as mesmas características acústicas. Considerando-se a variação da normalidade, não é incomum considerarmos uma bulha normal, para um determinado indivíduo, como sendo hiper ou hipofonética. Assim, ao mencionarmos que a segunda bulha é hiperfonética no foco pulmonar, como ocorre nos contextos de hipertensão pulmonar de diversas etiologias, estamos identificando tal sinal, ao compararmos a fonese da segunda bulha no foco pulmonar com a fonese da segunda bulha no foco aórtico. Do mesmo modo, quando dizemos que a primeira bulha é hiperfonética no foco mitral, como característico na estenose mitral, estamos comparando a sua intensidade no foco mitral com a do foco tricúspide, onde normalmente se apresentam as mesmas características acústicas.

Desdobramentos - Um mínimo desdobramento do primeiro ruído pode ser percebido em indivíduos normais, na porção inferior da borda esternal esquerda. Desdobramento amplo da primeira bulha ocorre, basicamente, devido ao retardo no aparecimento do componente tricúspide desse som. Situações clínicas, em que tal fenômeno pode se manifestar, incluem o bloqueio completo do ramo direito do feixe de His, a anomalia de Ebstein, a estenose tricúspide, e a estimulação elétrica do ventrículo esquerdo. No entanto, deve ser mencionado que o desdobramento do primeiro ruído não é documentado em todos os pacientes com tais condições clínicas.

O desdobramento anormal do segundo ruído cardíaco pode ocorrer na dependência de mecanismos diversos (Figura 4). Ele pode ser paradoxal, quando o fechamento da valva aórtica é tão retardado a ponto de o componente pulmonar ocorrer antes do aórtico. Assim, durante a expiração, o desdobramento será detectado, desaparecendo na inspiração, quando ocorre o retardo fisiológico do componente pulmonar. A situação clínica mais comumente associada ao desdobramento paradoxal é o bloqueio completo do ramo esquerdo do feixe de His. Esse tipo de desdobramento tem sido identificado em outras situações clínicas, que incluem a estenose aórtica, a persistência do canal arterial, e a hipertensão arterial sistêmica. No entanto, sua ausculta é, com freqüência, obscurecida pela presença de sopros, e sua ocorrência pouco freqüente. O desdobramento da segunda bulha pode ser, por outro lado, persistente, mas não fixo, significando que os dois componentes podem ser audíveis nas duas fases do ciclo respiratório, mantendo-se a variabilidade inspiratória do componente pulmonar, aumentando a separação dos dois componentes nessa fase. Tal padrão auscultatório pode ocorrer por retardo do componente pulmonar, como ocorre no bloqueio completo de ramo direito, ou por precocidade do componente

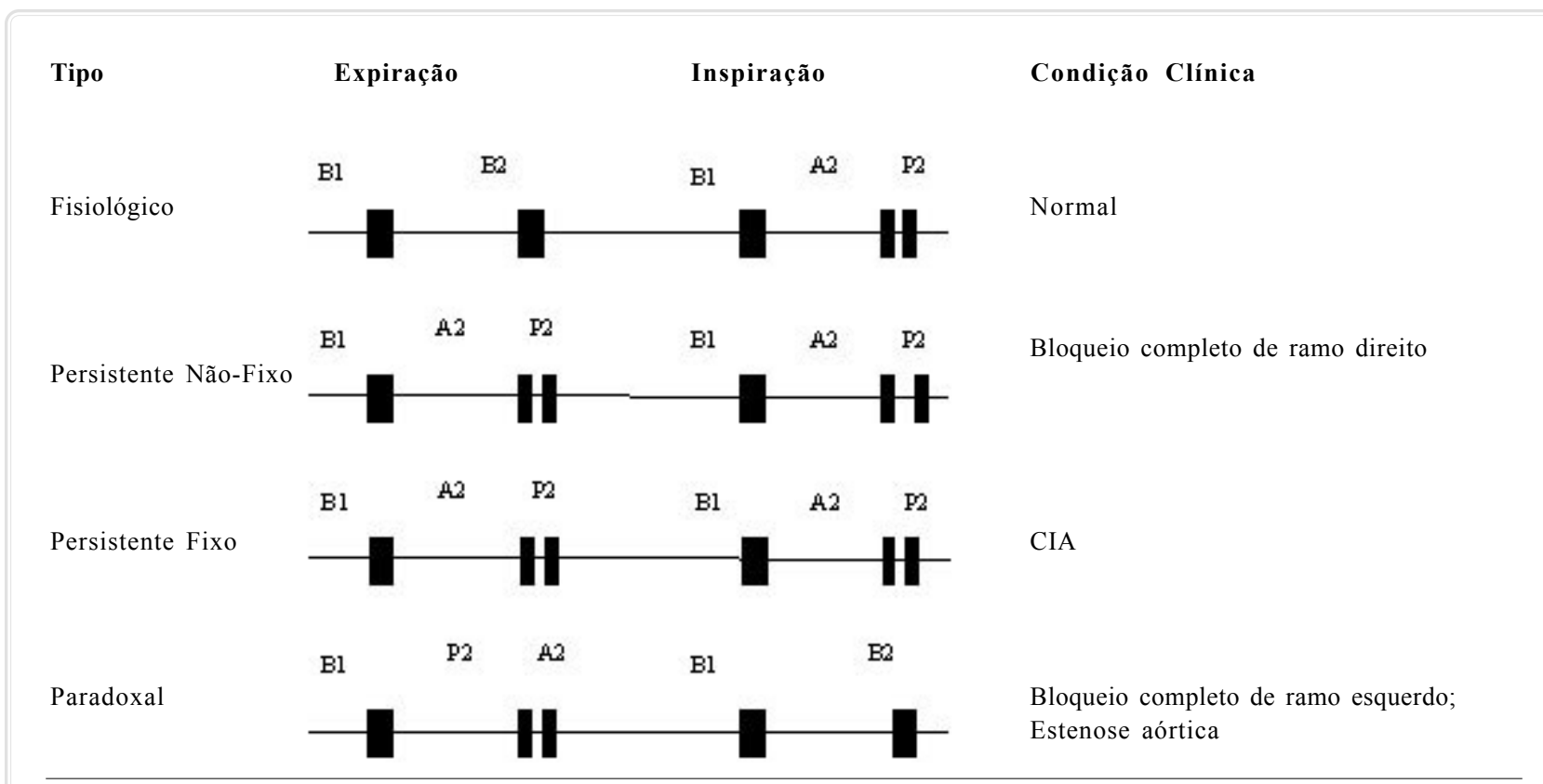

Figura 4: Desdobramentos da segunda bulha cardíaca. 
aórtico, tal como na insuficiência mitral. Finalmente, o desdobramento do segundo ruído pode ser persistente e fixo, quando estão amplamente separados os dois componentes durante as duas fases do ciclo respiratório, sem apresentar a variação inspiratória do componente pulmonar. (Figura 4). Tal padrão auscultatório é, classicamente, observado no defeito do septo atrial do tipo ostium secundum não complicado. Essa observação está associada à capacitância pulmonar persistentemente elevada em tal condição clínica, com pouca ou nenhuma variação respiratória. $\mathrm{O}$ enchimento ventricular direito apresenta variações respiratórias mínimas, uma vez que os efeitos respiratórios sobre o retorno venoso são contrapostos pela variação do volume de shunt esquerdo-direito durante o ciclo respiratório. Além disso, a sístole ventricular direita tem duração normal.

\section{8- RUÍDOS CARDÍACOS ADICIONAIS}

Além do primeiro e do segundo ruído, alguns sons adicionais podem ser auscultados durante o ciclo cardíaco, tanto em condições fisiológicas como em decorrência de cardiopatias diversas. Estão incluídos aqui a terceira e quarta bulhas cardíacas, os ruídos de ejeção e os clicks, bem como os sons de próteses valvares e marca-passos cardíacos. É fundamental reforçar aqui a importância da pesquisa sistematizada, rigorosa, da presença, ou não, de cada um desses sons. O sucesso na sua identificação depende, ainda, da utilização adequada das propriedades do estetoscópio em função das características sonoras de cada um desses ruídos.

Serão discutidas, inicialmente, a terceira e quarta bulhas cardíacas, devido a sua importância e caráter prognóstico.

\section{1- Terceira bulha cardíaca}

Mecanismos determinantes - $\mathrm{O}$ terceiro ruído cardíaco é um som transitório de baixa freqüência $(20-70 \mathrm{~Hz})$, que ocorre concomitantemente com a fase de enchimento rápido ventricular do ciclo cardíaco, durante a qual ocorre a maior parte do enchimento diastólico do ventrículo (aproximadamente 80\%). Esse som pode ser originário tanto do ventrículo direito como do esquerdo e, embora seu mecanismo seja fonte de alguma controvérsia, acredita-se que ele se origine como resultado da súbita limitação do movimento de expansão longitudinal da parede ventricular durante essa fase do ciclo cardíaco. Sua intensidade poderá ser fisiologicamente aumentada por manobras que promovam um incremento de velocidade de fluxo através das valvas atrioventriculares, como ocorre durante exercício físico dinâmico, ou por elevação dos membros inferiores. Do mesmo modo, a intensidade desse som também poderá estar anormalmente aumentada, quando ocorrerem situações clínicas que se associem a aumento do fluxo através de valvas atrioventriculares, como insuficiência mitral, febre, anemia, hipertireoidismo, ou quando os ventrículos apresentam anormalidades estruturais que modifiquem sua complacência e seu volume, como se verifica na insuficiência cardíaca.

O conhecimento das implicações prognósticas, associadas à terceira bulha é muito importante. No contexto do exame físico do adulto, resguardadas as outras etiologias listadas anteriormente, a terceira bulha é um marcador de disfunção sistólica do ventrículo esquerdo. Pode ser, inclusive, o único achado num paciente assintomático, que apresente disfunção sistólica do ventrículo esquerdo. Evidências recentes confirmam o caráter de evolução desfavorável dos pacientes que apresentam tal sinal.

Características auscultatórias - Por se tratar de um ruído de baixa freqüência, a terceira bulha será melhor audível com a campânula do estetoscópio posicionada adequadamente, e submetida a uma pressão mínima, suficiente apenas para um perfeito contato com a pele do paciente. Quando originada no ventrículo esquerdo, sua ausculta será melhor, se o paciente for posicionado em decúbito lateral esquerdo e a campânula estiver sobre o impulso apical (Figura 5). Por outro lado, ouve-se melhor o terceiro ruído de origem ventricular direito, na porção inferior da borda esternal direita ou região subxifóide. Do ponto de vista auscultatório, não existe diferença entre um terceiro ruído de origem fisiológica e outro patológico, ficando tal caracterização dependente dos elementos de ordem clínica. Do ponto de vista prático, a associação da terceira bulha com desvio do ictus cordis em direção à axila e para espaços intercostais inferiores, bem como o aumento de sua duração e extensão, denotando cardiomegalia, é um dos principais fatores que apontam para uma característica patológica do achado. A terceira bulha pode ser audível em crianças e adultos jovens, normais, mas existem evidências de que ela possa ser detectada em mulheres normais até a idade de 40 anos. 


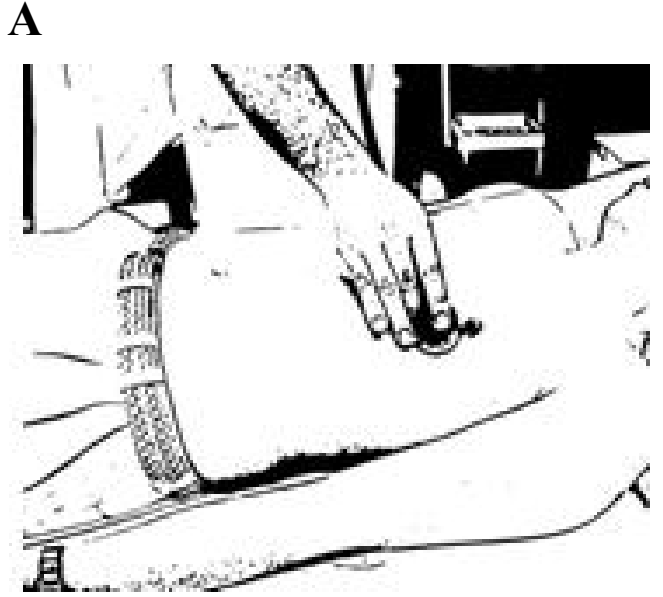

B

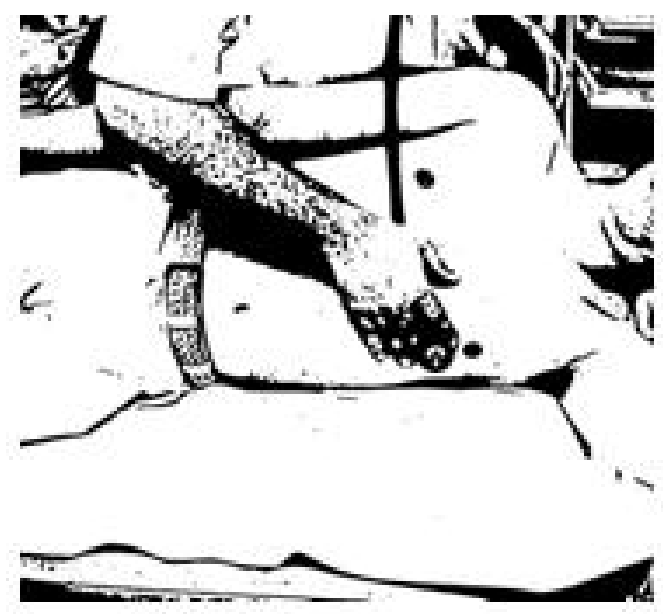

C

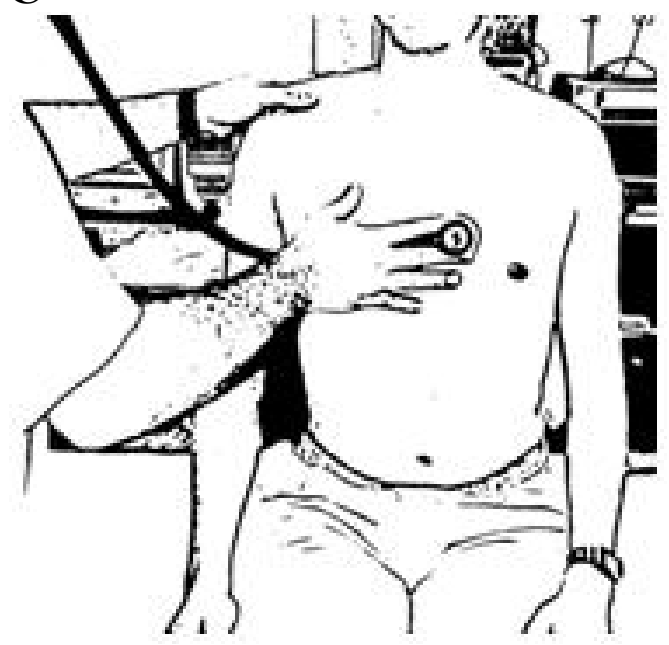

Figura 5: Posições para ausculta cardíaca. Vide texto para explicação.

\section{2- Quarta bulha cardíaca}

Mecanismos determinantes - É outro ruído que apresenta características físicas comparáveis às da terceira bulha, tanto do ponto de vista de freqüência como de duração. Ele demonstra uma relação temporal evidente com a contração atrial, sendo tipicamente um som pré-sistólico. Seu mecanismo provável parece estar relacionado com vibrações da parede ventricular, secundárias à expansão volumétrica dessa cavidade produzida pela contração atrial. Normalmente, sua intensidade é insuficiente para que seja audível em indivíduos normais, apesar de ser possível registrá-lo, facilmente, através da fonocardiografia. A quarta bulha cardíaca é detectada, com freqüência, em situações clínicas em que os ventrículos apresentem redução da complacência, tornando necessário um aumento da força de contração atrial para produzir o enchimento pré-sistólico dessa cavidade, tal como observado em hipertensão arterial sistêmica ou pulmonar, em estenose aórtica ou pulmonar, na miocardiopatia hipertrófica e, também, na doença isquêmica do coração. Na maior parte de tais situações clínicas, a avaliação do ictus cordis não apresenta sinais de cardiomegalia. Nessas condições, a contração atrial pode ser responsável por mais de $25 \%$ do volume de enchimento ventricular. Na ausência de contração atrial, como ocorre na fibrilação atrial, a quarta bulha não está presente.

A associação da quarta bulha com a presença de disfunção diastólica tem implicações prognósticas importantes. Por exemplo, no contexto da hipertensão arterial, implica em lesão de órgão-alvo, e justifica o tratamento mais agressivo da pressão arterial.

Características auscultatórias - Os mesmos cuidados técnicos utilizados na ausculta da terceira bulha são válidos para a quarta bulha, uma vez que as características físicas dos dois ruídos são similares, ao mesmo tempo em que ambos os sons são originários dos ventrículos. Apesar de alguma controvérsia, considera-se que a ausculta de quarta bulha representa um indicador de anormalidade do enchimento ventricular. Alguns, no entanto, admitem que a quarta bulha, auscultada em indivíduos idosos, sem cardiopatia clinicamente detectada, represente um fenômeno normal.

\section{3- Ruídos de marca-passo}

O som de marca-passo é um ruído que se manifesta logo após o estímulo elétrico de marca-passos ventriculares direitos, sendo, como a quarta bulha, um 
ruído pré-sistólico. É um som de alta freqüência, com timbre estalante, bem distinto do padrão auscultatório da quarta bulha, e que se acredita ter origem extracardíaca. Admite-se que ele seja gerado pela contração de músculos da parede torácica, secundária à estimulação elétrica do marca-passo.

Na dependência da freqüência cardíaca, a ausculta do terceiro e/ou quarto ruídos pode dar origem aos ritmos de galope, que podem ser caracterizados pela ausculta isolada de cada um desses ruídos, ou, quando existe um intervalo diastólico curto ou um intervalo P-R longo, pode ocorrer coincidência temporal entre esses sons, resultando no galope de soma.

\section{4- Ruídos de ejeção (clicks proto-sistólicos)}

São ruídos transitórios, de alta freqüência, com timbre que lembra um estalido de curta duração, que ocorrem logo após o primeiro ruído, relacionando-se, temporalmente, à ejeção ventricular. Dois mecanismos têm sido propostos para sua gênese: vibrações decorrentes da tensão a que os folhetos de valvas semilunares estenóticas seriam submetidos durante sua abertura na sístole, ou associadas à distensão súbita das artérias durante a ejeção ventricular. Existem indícios de que os dois mecanismos possam estar implicados na gênese do ruído. Sua ocorrência está associada a anormalidades estruturais de valvas semilunares e/ou dos vasos da base, que, normalmente, se apresentam dilatados em tais condições. Não são, portanto, audíveis em indivíduos normais. Podem ocorrer no lado sistêmico da circulação, em decorrência da estenose valvar aórtica, valva aórtica bicúspide, ou dilatação da raiz da aorta. Quando ocorrem associados à doença valvar, indicam uma valva não calcificada, com boa mobilidade, embora sem relação com a gravidade da estenose. Por outro lado, ruídos de ejeção podem ocorrer no lado direito da circulação, associados à estenose valvar pulmonar, hipertensão arterial pulmonar, ou dilatação idiopática da artéria pulmonar. $\mathrm{Na}$ estenose valvar pulmonar, observa-se tendência ao desaparecimento do ruído de ejeção durante a inspiração. Além disso, o intervalo de aparecimento, em relação à primeira bulha, tende a ser tanto mais curto quanto maior a gravidade da estenose. E'um ruído habitualmente detectado sem dificuldade, quando ocorre, pelo menos, $50 \mathrm{~ms}$ após a primeira bulha. Suas características de freqüência (tonalidade) são similares às da primeira e segunda bulhas, diferenciando-se delas pelo timbre. Assim, esses sons são auscultados em melhores condições quando se utiliza o diafragma do estetoscópio. Os ruídos de ejeção aórticos são melhor audíveis sobre o foco aórtico e na região apical, enquanto aqueles originados no lado direito são detectados no foco pulmonar. Ruídos proto-sistólicos de características auscultatórias similares também ocorrem em pacientes portadores de próteses metálicas em posição aórtica, mas não são detectados em portadores de próteses biológicas.

É importante estabelecer, do ponto de vista auscultatório, o diagnóstico diferencial de ruídos que ocorrem temporalmente próximos, como a quarta bulha, a primeira bulha desdobrada, e o ruído de ejeção. Devese lembrar que a quarta bulha corresponde a um ruído pré-sistólico, de baixa freqüência, que apenas será audível, adequadamente, com a campânula do estetoscópio submetida à pressão mínima e, quando originado do lado esquerdo do coração, o que é mais freqüente, em decúbito lateral esquerdo. Assim, a quarta bulha tem características sonoras que não se superpõem ao desdobramento e aos ruídos de ejeção. A diferenciação entre esses dois ruídos é um pouco mais complexa, uma vez que ambos são sons de alta freqüência (tonalidade) e ocorrem no início da sístole. Sua distinção baseia-se, fundamentalmente, no timbre de estalido do ruído de ejeção. Além disso, o desdobramento de B1, geralmente, é identificado na porção inferior da borda esternal esquerda, enquanto o ruído de ejeção é melhor audível nos focos da base do coração, e costuma ser mais intenso que o componente tricúspide do primeiro ruído. No entanto, a diferenciação auscultatória nem sempre é possível. Nesse sentido, é importante utilizar o conjunto das informações clínicas para adequada interpretação da ausculta cardíaca. Um dado interessante, que pode auxiliar na distinção entre um click de ejeção e um desdobramento da primeira bulha, é que, geralmente, o primeiro vem acompanhado de um sopro sistólico protomesossistólico (ou ejetivo).

\section{5- Ruídos mesotelessistólicos (clicks)}

Correspondem a ruídos de alta freqüência, de curta duração, que têm timbre de estalido e ocorrem na porção média ou final da sístole. A causa mais freqüente desse tipo de estalido é o prolapso de valva mitral, admitindo-se que sua gênese, nesse caso, estaria relacionada à tensão súbita a que os folhetos redundantes e cordas tendíneas são submetidos na sístole ventricular. Em tal condição clínica, pode-se auscultar apenas um ou, até mesmo, vários desses ruídos, em seqüência. Manobras fisiológicas, que reduzem o enchimento ventricular esquerdo, como a inspiração, a posição ortostática, a inalação de nitrito de amilo, ou a 
manobra de Valsalva, fazem com que o estalido ocorra mais precocemente. Algumas estruturas extracardíacas têm sido implicadas na gênese de ruídos mesossistólicos, incluindo sons de origem pericárdica ou relacionados a pneumotórax.

\section{6- Estalidos de abertura de valvas atrioventri- culares}

Enquanto, em condições normais, a abertura das valvas atrioventriculares não está habitualmente associada à ocorrência de sons, quando estenóticas, elas podem determinar o aparecimento de ruídos de alta freqüência, com timbre de estalido, que surgem, em média, entre 40 e $60 \mathrm{~ms}$ após o componente aórtico da segunda bulha. Admite-se que sua gênese dependa da tensão súbita a que são submetidos os folhetos das valvas A-V durante sua abertura incompleta, no início da diástole, na presença de um gradiente de pressão maior que o da situação normal, não patológica. A estenose mitral é, certamente, a condição clínica em que mais comumente esse tipo de som é identificado. Sua presença é um indicador clínico de que, pelo menos, o folheto anterior da mitral apresenta mobilidade satisfatória, enquanto que sua ausência, na estenose mitral pura, indica a possibilidade de calcificação dos folhetos valvares, ou estenose muito leve. Nessa condição clínica, o intervalo entre o estalido de abertura e o componente aórtico do segundo ruído tende a ser tanto mais curto quanto maior a gravidade hemodinâmica da estenose. Pelas características físicas, esse ruído é melhor audível com o diafragma do estetoscópio posicionado na porção inferior da borda esternal esquerda, mas ele também pode ser percebido na região apical e nos focos da base. A diferenciação entre o estalido de abertura da mitral ou tricúspide, e a presença de segunda bulha desdobrada, não é tão simples, uma vez que ambos são sons de freqüência relativamente elevada. Alguns elementos, no entanto, podem auxiliar na distinção: o timbre do estalido tende a ser diferente daquele de P2, sua irradiação é mais ampla, e sua relação com $\mathrm{A} 2$ não varia com a respiração, ao contrário do que ocorre com P2. Contudo, existem algumas situações em que é praticamente impossível distinguir clinicamente os dois ruídos, especialmente quando a estenose mitral grave se associa à hipertensão arterial pulmonar. $\mathrm{O}$ estalido de abertura não deve ser confundido com a presença de terceira bulha, uma vez que este é um ruído de baixa freqüência, mais tardio (geralmente ocorre mais de $120 \mathrm{~ms}$ após a A2), tanto que muitos autores o classificam como um ruído mesodiastólico.
Além do estalido de abertura das valvas A-V existem outros ruídos proto-diastólicos, identificáveis clinicamente. Em algumas condições, tais como o duto arterioso persistente, o defeito do septo ventricular, a tireotoxicose, a miocardiopatia hipertrófica e, com maior destaque, a insuficiência mitral, pode ocorrer aumento do fluxo anterógrado através das valvas A$\mathrm{V}$. Na dependência de condições de complacência ventricular anormal, a descompressão rápida do átrio esquerdo hipertenso pode determinar um movimento rápido e amplo das valvas $\mathrm{A}-\mathrm{V}$ normais, que, quando interrompido, geraria o ruído protodiastólico. Um mecanismo similar parece ser responsável pelo ruído observado no início da diástole, em pacientes com pericardite constrictiva (pericardial knock). Nessa condição, o enchimento ventricular ocorre, predominantemente, no início da diástole, de modo que a súbita interrupção da expansão ventricular criaria as condições para o ruído protodiastólico. Ele tende a ser mais precoce (90-120 ms), e também apresenta tom mais agudo que o terceiro ruído. A presença de um mixoma atrial direito ou esquerdo, pedunculado pode oferecer as condições para outro tipo de ruído protodiastólico. É um som, de baixa freqüência, que ocorre entre 80 e $130 \mathrm{~ms}$ depois de A2, tem características similares à terceira bulha, e parece ocorrer como conseqüência do movimento abrupto do tumor em direção ao orifício valvar na diástole (tumor plop).

A abertura de próteses metálicas em posição mitral também se acompanha de produção de ruídos protodiastólicos, que geralmente são mais intensos com próteses do tipo Starr-Edwards. As próteses biológicas não originam ruídos desse tipo durante a diástole ventricular.

\section{9- SOPROS CARDÍACOS}

Comparativamente aos sons descritos até aqui, os sopros cardíacos correspondem a um conjunto de vibrações de duração bem mais prolongada, que surgem quando o sangue modifica o seu padrão laminar de fluxo, tornando-se turbulento. A turbulência pode ocorrer como resultado de um aumento desproporcional da velocidade do fluxo sangüíneo relativamente às dimensões das estruturas através das quais ele se movimenta. Assim, sopros podem se originar quando o sangue atravessa orifícios restritivos, como ocorre em estenoses e insuficiências valvares, em obstruções arteriais, na coarctação da aorta, e em pequenas comunicações interventriculares ou em estados de hiperfluxo transvalvar, como na comunicação interatrial 
e em estados circulatórios hiperdinâmicos, ou, ainda, quando ele flui através de dilatações vasculares, como acontece em dilatações da aorta e da artéria pulmonar. Existe um conjunto de características fundamentais, que devem ser exploradas na avaliação de sopros cardíacos, incluindo: fase do ciclo em que ocorrem, duração, intensidade, freqüência (tonalidade), timbre, configuração, localização, irradiação e relação com a respiração. A adequada abordagem clínica dos sopros cardíacos exige cuidadosa pesquisa para caracterização detalhada dos elementos mencionados, que, em conjunto, permitirão identificar o processo fisiopatológico, determinante do ruído cardíaco. Isso implica numa abordagem sistematizada, que busque analisar, individualmente, cada uma das características, utilizando-se as propriedades do estetoscópio que mais se ajustem a cada tipo de sopro.

\section{1- Características descritivas dos sopros car- díacos}

Fase do ciclo cardíaco - Os sopros são caracterizados como sistólicos, quando ocorrem entre o primeiro e o segundo ruídos, diastólicos ao incidir entre a segunda e a primeira bulhas, ou, ainda, contínuos, ao ocorrerem nas duas fases do ciclo, incorporando, sem interrupção, o segundo ruído.

Duração - De acordo com a duração, desde o momento de início até o seu término, um sopro sistólico pode ser caracterizado com proto, meso, tele ou holossistólico, no caso de a vibração ocorrer predominantemente no início, meio, final ou ao longo de toda a sístole, respectivamente. Do mesmo modo, os sopros diastólicos também podem ser caracterizados de proto, meso, tele ou holodiastólicos.

Intensidade - Essa característica é dependente da interrrelação de diversos fatores, incluindo a distância entre o local de origem da turbulência e a região de ausculta, a velocidade do sangue, e o fluxo sangüíneo através do local de produção do sopro, bem como das condições de transmissão desse som até a superfície do tórax. Assim, a intensidade dos sopros tende a aumentar em indivíduos de tórax pouco espesso e em crianças, enquanto eles tendem a apresentar menor intensidade em pacientes obesos, com doença pulmonar obstrutiva crônica, ou derrame pericárdico. Do mesmo modo, eles aumentam em condições hiperdinâmicas da circulação e diminuem em estados de hipofluxo. Genericamente, os sopros cardíacos são caracterizados de acordo com a intensidade em 6 níveis, a saber: grau I/ $6=$ representa um sopro tão pouco intenso que só pode ser ouvido com muito esforço e concentração; grau II/6= sopro de pequena intensidade mas que pode ser identificado rapidamente por um observador experiente; grau III $/ 6=$ sopro bem marcante mas não muito intenso; grau IV/6= sopro intenso; grau V/6= sopro muito intenso e grau $\mathrm{VI} / 6=$ sopro tão intenso que pode ser audível mesmo quando o estetoscópio não está em contato direto com a parede do tórax. Ainda que tal classificação seja utilizada desde a década de 30 , devese registrar que ela envolve um grau substancial de subjetividade, o que, no entanto, é inevitável. Sua utilidade clínica, apesar disso, é inquestionável. Uma regra prática para a distinção da intensidade dos sopros é atentar para a presença de frêmitos. Quando existir frêmito, o sopro apresenta intensidade de IV, V ou VI em 6.

Freqüência (tonalidade) - A freqüência de um sopro, geralmente, tem relação direta com a velocidade do sangue no local onde o ruído é gerado. O espectro de variação dos ruídos e sopros cardíacos não é muito amplo, estando entre 20 e $500 \mathrm{~Hz}$. Ainda que tal faixa esteja situada na região de baixas freqüências do espectro de audibilidade do ouvido humano, do ponto de vista clínico, considera-se que sons com freqüências entre 20 e $100 \mathrm{~Hz}$ são de baixa freqüência, enquanto aqueles que estão entre 100 e $200 \mathrm{~Hz}$ têm freqüências médias, e aqueles com freqüência entre 200 e $500 \mathrm{~Hz}$ são considerados de alta freqüência. Assim, esses sons poderão ser caracterizados clinicamente, com base na variação de freqüências, como sopros graves ou agudos.

Timbre - A caracterização do timbre (qualidade) de um sopro depende do espectro de freqüências (harmônicas) que o compõem. Um conjunto variado de termos tem sido empregado na descrição dessa característica dos sopros, incluindo: rude, áspero, suave, musical, aspirativo, em ruflar. Cada um deles tem aplicação específica para determinados tipos de sopros, como será descrito posteriormente.

Configuração - A forma de um sopro representa a maneira pela qual a intensidade do som se distribui ao longo do tempo.Assim, eles podem ser descritos como em crescendo, quando sua intensidade aumenta progressivamente, enquanto o contrário ocorre nos sopros em decrescendo. No sopro crescendo-decrescendo, a intensidade aumenta no início, atinge um pico e depois se reduz progressivamente. $\mathrm{O}$ sopro em plateau mantém uma intensidade constante ao longo de toda a ocorrência. Nem todos os sopros podem ser enquadrados em tais configurações, uma vez que apresentam intensidade variável no tempo. 
Localização e Irradiação - É fundamental, na avaliação dos sopros cardíacos, identificar o local em que se manifestam com maior intensidade, uma vez que tal dado é utilizado na determinação do local de origem. Nesse sentido, a ausculta não deve ser executada apenas nos focos auscultatórios clássicos. Ela deve incluir, além desses focos, o mesocárdio, as bordas esternais esquerda e direita, a região subxifóide, e áreas de irradiação freqüente de sopros, como a região axilar, região subclavicular, fúrcula e base do pescoço. $\mathrm{Na}$ dependência de outros elementos clínicos, mesmo na parede posterior do tórax, tal abordagem deve ser realizada. Desde que um sopro seja dectectado, deve-se procurar, a partir de pequenos movimentos do estetoscópio, a região de maior intensidade. Essa movimentação também permitirá definir o padrão de irradiação do sopro, outro elemento importante na caracterização clínica desses sons cardíacos.

Relação com a respiração - A intensidade dos sopros originados nas câmaras cardíacas direitas sofre influência da respiração. Durante a inspiração, o aumento do retorno venoso para as câmaras direitas, que ocorre devido à diminuição da pressão intratorácica, ocasiona o aumento transitório da intensidade do sopro. O fenômeno é conhecido como Sinal de Rivero-Carvallo, é melhor explorado com o estetoscópio colocado no foco tricúspide, pedindo-se ao paciente que realize incursões inspiratórias lentas e prolongadas, de modo similar ao do método utilizado, previamente, para explorar o desdobramento fisiológico da segunda bulha.

\section{2- Sopros sistólicos}

São sopros clinicamente descritos, de acordo com sua duração ao longo da sístole, como mesossístólicos, holossistólicos, protossistólicos e telessistólicos. Do ponto de vista da prática diária, merecem destaque, pois são prevalentes. Variam desde situações em que são ditos inocentes, como são chamados os sopros não associados a dano estrutural cardíaco e audíveis em crianças e adultos jovens, até situações de prognóstico sombrio, como é o caso da estenose aórtica.

Em que se pesem essas considerações, dentre os vários tipos que serão discutidos, os sopros mesossistólicos e os sopros holossistólicos são os prevalentes, e na maioria das situações clínicas, o maior desafio reside na distinção entre esses dois tipos de sopros. Uma regra prática para sua distinção consiste em prestar atenção na segunda bulha cardíaca: os sopros mesossistólicos diminuem de intensidade antes da segunda bulha, sendo fácil a sua percepção, en- quanto os sopros holossistólicos persistem até a segunda bulha, "apagando" a sua expressão. A comparação entre as características desses dois tipos de sopros pode ser vista na Figura 6.

\section{Sopros mesossistólicos}

Para exemplificar a gênese desse tipo de sopro, utilizaremos a estenose aórtica, uma das condições clínicas mais representativas.

Observe a Figura 6. Nela, pode-se notar que a presença da estenose aórtica impõe um gradiente de pressão entre o ventrículo e a aorta, de magnitude de cerca de 80 a $100 \mathrm{mmHg}$, gradiente que se estabelece, efetivamente, apenas após o ponto em que o ventrículo ultrapassa a pressão da aorta. Portanto, as condições para que o sopro seja gerado só começam a existir alguns milissegundos após o fechamento da mitral, ou seja, o sopro não se inicia concomitantemente com a primeira bulha, embora, devido ao fato desse retardo, não seja tão pronunciado, em uma grande parte das situações clínicas, temos a impressão de que o sopro começa com a primeira bulha. Durante a sístole, à medida que o gradiente vai aumentando, a intensidade do sopro também aumenta, fazendo com que ele seja mais intenso no meio da sístole. Com o relaxamento ventricular no final da sístole, o gradiente diminui, conjuntamente com o sopro, o que torna possível que percebamos com nitidez a segunda bulha. Essa condição hemodinâmica é a responsável pela característica em crescendo-decrescendo apresentada na Figura 6, traduzida na ausculta cardíaca por um timbre dito ejetivo.

Tal tipo de sopro ocorre em condições clínicas diversas, que incluem: obstruções ao fluxo em via de saída dos ventrículos (estenose aórtica ou pulmonar em região subvalvar, valvar ou supravalvar), hiperfluxo através das valvas semilunares (comunicação interatrial, anemia, exercício, febre, hipertireoidismo, gravidez, bloqueio A-V total), dilatação da aorta ou do tronco pulmonar, e anormalidades estruturais em valvas semilunares (degeneração senil da valva aórtica).

A maior parte dos sopros ditos inocentes, que ocorrem predominantemente em crianças e jovens adultos, são também, tipicamente, mesossistólicos ejetivos. Os sopros inocentes podem se originar nos folhetos das valvas pulmonar e aórtica, no tronco pulmonar e em ramos da artéria pulmonar, podendo ter sua ausculta facilitada pela proximidade desse vaso com a parede torácica, como ocorre em pacientes que têm uma dimensão ântero-posterior do tórax diminuída (perda da cifose torácica). É a associação com outros achados de exame físico, por exemplo, a presença de 
frêmito, bem como dados de história clínica, que servirão para distinguir os sopros inocentes de sopros estruturais. Estes sopros podem apresentar um timbre bastante rude e áspero e são observados nas estenoses valvares, aórtica e pulmonar, ou suave, como verificado nos sopros inocentes, nas dilatações vasculares e no hiperfluxo transvalvar pulmonar ou aórtico.

Nem todos os sopros mesossistólicos são ejetivos. Algumas formas de regurgitação mitral, como acontece em alguns pacientes com disfunção de músculo papilar, podem apresentar um sopro mesossistólico, que não está relacionado com a ejeção ventricular.

\section{Sopros holossistólicos}

Para exemplificar a gênese desse tipo de sopro, utilizaremos a insuficiência mitral, como sendo a condição clínica mais representativa.

Observe a Figura 6. Nela, pode-se notar que a presença da insuficiência mitral impõe um gradiente de pressão entre o átrio e o ventrículo de magnitude de cerca de $100 \mathrm{mmHg}$. Tal gradiente pode ser extremamente variável, na dependência da complacência atrial. Numa situação de insuficiência mitral crônica, na qual a complacência atrial, em geral, é grande, o gradiente entre o átrio e o ventrículo esquerdo durante a sístole, também assume proporções significativas. Pode se observar, na Figura 6, que o gradiente se estabelece, efetivamente, quando a válvula mitral se fecha, e persiste durante toda a sístole. Mesmo que ocorra a diminuição do gradiente, com a elevação da pressão atrial, no final da sístole, o gradiente ainda persiste da ordem de $50 \mathrm{mmHg}$. Portanto, as condições para que o sopro seja gerado começam a existir, concomitantemente, com a primeira bulha, e persistem até a segunda bulha. Na realidade, a segunda bulha é encoberta pelo sopro, dando-nos a impressão de estar "apagada" ou mesmo ausente. Essa condição hemodinâmica é a responsável por tal característica em plateau, apresentada na Figura 6, traduzida na ausculta cardíaca por um timbre dito regurgitativo.

Ainda que, com freqüência, esses sopros sejam referidos como regurgitativos, eles não são causados apenas pelo fluxo retrógrado através das valvas atrioventriculares, podendo estar relacionados ao fluxo através de comunicações intraventriculares. Eles dependem, freqüentemente, de grandes gradientes de pressão através de orifícios pequenos, o que determina seu padrão da alta freqüência. Eles ocorrem nas insuficiências valvares, mitral e tricúspide, na comunicação interventricular com orifício restritivo, e em comunicação entre as grandes artérias, como no caso de janelas aortopulmonares, e canal arterial persistente, associados a resistência vascular pulmonar elevada, eliminando o fluxo diastólico através do defeito. Os sopros holossistólicos das insuficiências valvares apresentam, geralmente, timbre mais suave, enquanto aqueles relacionados à comunicação interventricular apresentam-se mais rudes. Uma característica diferencial importante do sopro holossistólico da insuficiência tricúspide é o característico aumento inspiratório da intensidade do sopro (sinal de Rivero-Carvallo) que, geralmente, não se manifesta quando a função ventricular direita mostra-se muito alterada. Embora o sinal de Rivero-Carvallo seja utilizado na distinção entre sopros holossistólicos de origem ou tricúspide ou mitral, outros sinais semiológicos, como a inspeção do pulso jugular e do precórdio, são mais fidedignos para a percepção de insuficiência tricúspide significativa.

Além dos dois tipos de sopros apontados acima, outros dois tipos de sopros sistólicos são encontrados.

\section{Sopros protomesossistólicos}

São sopros que se iniciam com a primeira bulha, estendem-se pela parte inicial da sístole, e tendem a decrescer e desaparecer até a metade dessa fase do ciclo. Podem ocorrer nas insuficiências mitral e tricúspide, agudas, graves, e o seu desaparecimento ao final da sístole, parece depender da tendência à equalização das pressões ventricular e atrial, nesse momento do ciclo. Do mesmo modo, tal tipo de sopro também é descrito em comunicações interventriculares, associadas à resistência vascular pulmonar elevada, quando o fluxo através do defeito pode ser desprezível ao final da sístole. Em defeitos muito pequenos do septo ventricular, às vezes, documenta-se um sopro protomesossistólico.

\section{Sopros mesotelessistólicos}

São assim catalogados os sopros que se iniciam na metade, ou no final da sístole e se prolongam até o segundo ruído. O exemplo clássico desse tipo de sopro é aquele identificado no prolapso valvar mitral, que muitas vezes, inclusive, é precedido por um ou mais clicks meso-sistólicos. Apresentam alta freqüência, têm timbre suave, mas ocasionalmente podem ser musicais.

\section{3- Sopros diastólicos}

Nesse caso, o critério de classificação clínica de tal tipo de sopro é o momento da diástole em que se inicia. Assim, eles podem ser proto, meso ou telessistólicos se, respectivamente, iniciam-se com o segundo ruído ou após um evidente intervalo subseqüente à segunda bulha, ou, finalmente, ocorrem imediatamente antes do primeiro ruído. Genericamente, eles 


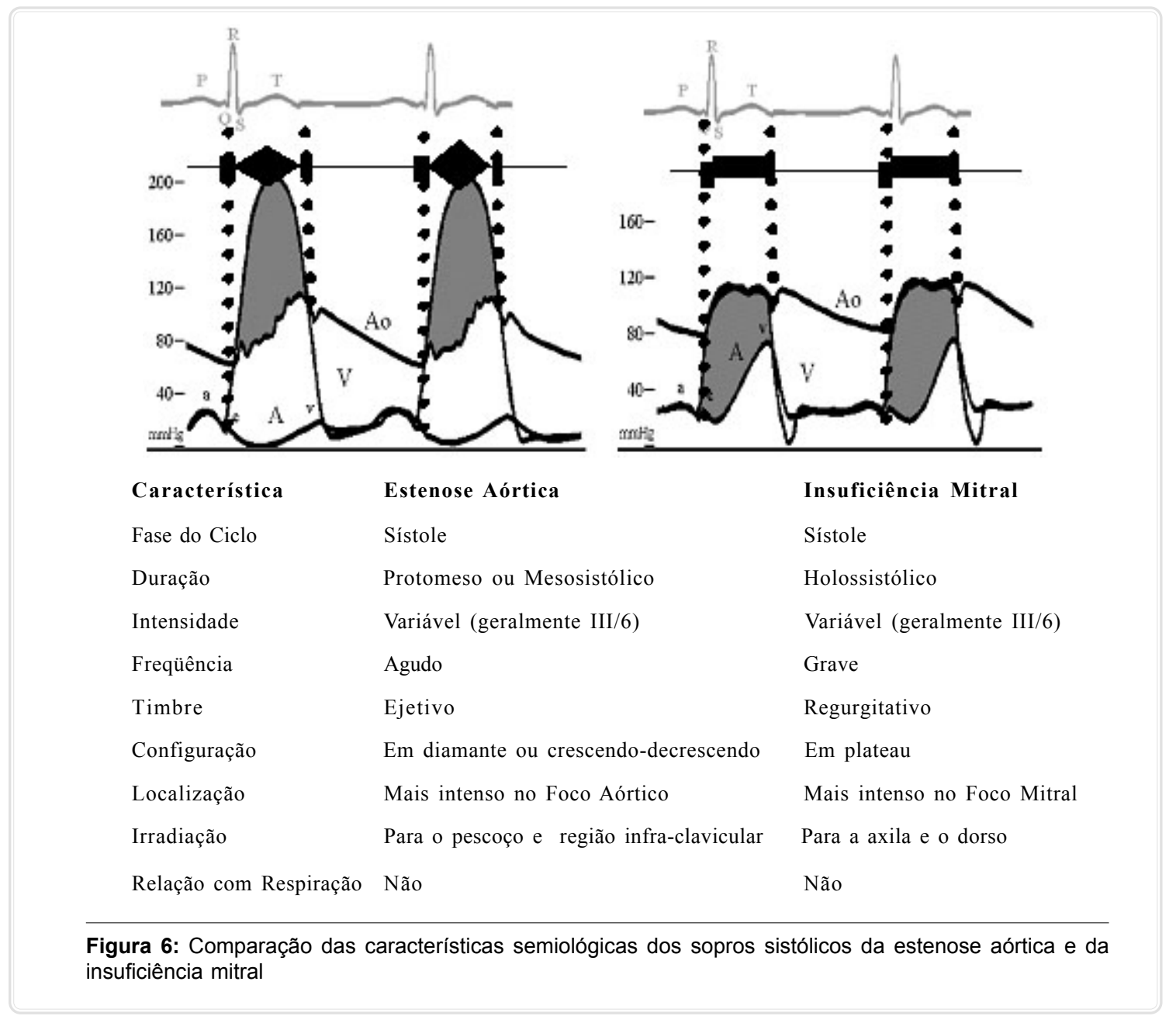

podem se originar de regurgitação através de valvas semilunares ou como resultado do fluxo anterógrado através de valvas atrioventriculares.

Ao contrário dos sopros sistólicos, cuja interpretação clínica pode variar desde um sopro inocente até uma condição clínica com prognóstico mais reservado, os sopros diastólicos são sempre considerados patológicos e demandam investigação. Tal fato torna a sua detecção, embora mais difícil, como exposto a seguir, de suma importância.

Dos diferentes tipos existentes, na grande maioria das situações clínicas, a distinção será necessária entre os sopros protodiastólicos e os sopros tele-diastólicos.

Sopros protodiastólicos - Para explicar a gênese dos sopros protodiastólicos, utilizaremos a insuficiência aórtica.

Observe a Figura 7. Pode-se observar que, devido à insuficiência valvar aórtica, ocorre um decréscimo da pressão arterial diastólica ao longo da diástole, ocasionando pressão arterial divergente. Como esta- mos utilizando como exemplo uma situação de insuficiência crônica, o ventrículo apresenta-se complacente e não apresenta elevação da pressão diastólica final. A queda da pressão arterial diastólica se inicia logo após o ponto em que a pressão do ventrículo cai abaixo da pressão aórtica no início da diástole, ou seja, logo após a segunda bulha. É o momento em que o gradiente de pressão entre a aorta e o ventrículo é maior e, portanto, a intensidade do sopro é maior nessa porção da diástole. Com a progressão da diástole, a queda da pressão arterial diastólica faz com que o gradiente de pressão entre a aorta e o ventrículo diminua e, conseqüentemente, a intensidade do sopro também diminua. Essa condição hemodinâmica é a responsável pela característica em decrescendo de tal sopro, com timbre dito aspirativo, quando predominam os componentes de alta freqüência, que caracterizam a insuficiência aórtica crônica, mas pode ser curto e composto de freqüências sonoras mais baixas na insuficiência aórtica aguda. São sopros que se iniciam 
com o segundo ruído e podem estender-se por toda a diástole, ainda que sua intensidade tenda a decrescer continuamente. Além de na insuficiência aórtica, podem ocorrer na insuficiência pulmonar.

Para a correta observação semiológica desses sopros, o foco de melhor percepção se constitui no foco aórtico acessório, representado na Figura 3. A ausculta na posição sentada, com o estetoscópio sobre os focos da base, como demonstrado na Figura 4, também é útil. Vale ainda ressaltar que, como todo evento diastólico de alta freqüência, o uso do diafragma pode ser crucial para a correta percepção.

Embora não seja o objetivo desta revisão, vale ressaltar que, em especial, no contexto da insuficiência aórtica, a pressão arterial divergente pode ocasionar uma série de sinais periféricos, indicativos da severidade da lesão valvar e, muitas vezes, mais expressivos que o próprio sopro, em particular nos casos de lesões valvares associadas.

Sopros mesodiastólicos ou telediastólicos:

Para explicar a gênese dos sopros meso e telediastólicos, utilizaremos a estenose mitral.
Observe a Figura 7. A restrição ao enchimento ventricular esquerdo, decorrente de dificuldade de abertura da valva mitral, ocasiona a elevação da pressão no interior do átrio esquerdo. É o mecanismo responsável pelo surgimento de gradiente de pressão entre o átrio esquerdo e o ventrículo esquerdo, da ordem de 15 a $20 \mathrm{mmHg}$. Para que o sopro comece a existir, a valva mitral deve se abrir, o que só acontece quando a pressão do ventrículo esquerdo cai abaixo da pressão do átrio, temporalmente, não coincidindo com a segunda bulha cardíaca (quando a pressão do ventrículo cai abaixo da da aorta), o que explica porque tais sopros não são ouvidos junto com a segunda bulha, estando mais audíveis a partir do meio da diástole.

Da Figura 7, também se depreende, como anteriormente ressaltado, que a contração atrial passa a ser importante para o enchimento atrial, exacerbando o gradiente atrioventricular no final da diástole e tornando a contribuição atrial maior do que os $25 \%$ com que normalmente contribui para o enchimento atrial, o que é o motivo da exacerbação que tais sopros podem apresentar imediatamente antes da primeira bulha,

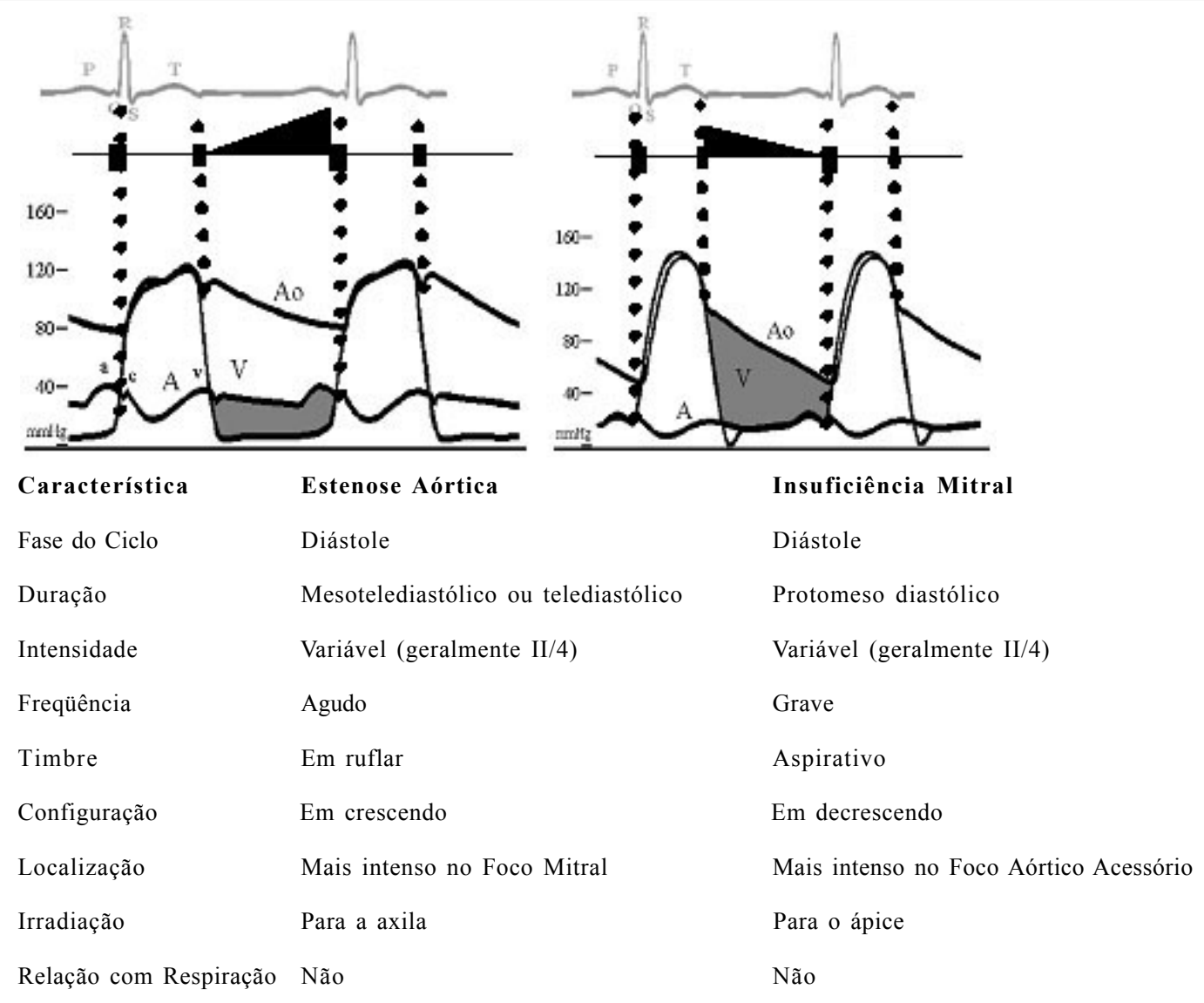

Figura 7: Comparação das características semiológicas dos sopros diastólicos da estenose mitral e da insuficiência aórtica 
quando ocorre a contração atrial. Devido a essa característica, são ditos telediastólicos ou pré-sistólicos. Como eles dependem do efeito da contração atrial sobre o fluxo transvalvar, esses sopros não ocorrem quando o ritmo cardíaco é de fibrilação atrial. Têm, habitualmente, configuração em crescendo e padrão de tonalidade composto por baixas freqüências de ondas sonoras, sendo melhor audíveis com a campânula do estetoscópio.

Além da estenose mitral, podem ser observados, também, como conseqüência de um excessivo aumento do fluxo anterógrado através de valvas $\mathrm{A}-\mathrm{V}$ normais (insuficiência mitral, comunicação interventricular e canal arterial persistente), na comunicação interatrial (em que o fluxo através da valva tricúspide é excessivo), e na insuficiência da valva pulmonar, associada à pressão arterial pulmonar normal. Em todas essas condições, o sopro diastólico tende a ser messodiastólico.

No contexto geral, são sopros que apresentam baixa freqüência (menos que $150 \mathrm{~Hz}$ ), sendo melhor perceptíveis com a campânula do estetoscópio. Em particular, nos sopros telediastólicos da estenose mitral, a utilização do decúbito lateral esquerdo, com a colocação da campânula sobre o foco mitral (ictus cordis) pode favorecer sua percepção.

\section{4- Sopros contínuos}

São classificados como contínuos os sopros que têm início na sístole e se estendem através do segundo ruído, envolvendo parte ou, até mesmo, toda a diástole. Eles ocorrem em condições em que existe comunicação entre segmentos da circulação com grande diferencial de pressão, que se mantém ao longo de todo o ciclo cardíaco, como acontece na persistência do canal arterial, nas fístulas arteriovenosas, na ruptura do seio de Valsalva em cavidades cardíacas direitas, e na janela aortapulmonar. Sopros contínuos também podem ser detectados na projeção de artérias normais, como acontece na região mamária de mulheres ao final da gravidez ou na lactação, vindo a representar um sopro inocente. Às vezes, tal sopro mamário é predominantemente sistólico. Do mesmo modo, sopros contínuos podem ser percebidos em pacientes com cardiopatias cianosantes graves, quando, então, estão relacionados com a presença de circulação colateral abundante. Sopros contínuos também podem ser detectados na base do pescoço, em crianças normais e adultos jovens, bem como em pacientes com anemia, hipertireoidismo ou em mulheres grávidas. São melhor audíveis com a campânula do estetoscópio posicionada na região lateral da fossa supraclavicular direita, submetida à mínima pressão, estando o paciente sentado, com a cabeça voltada para o lado esquerdo.

\section{0- ATRITO PERICÁRDICO}

São ruídos de duração relativamente prolongada, que podem ocorrer tanto na sístole como na diástole, concomitantemente ou de modo isolado, sendo descritos como sons rudes ou ásperos à ausculta, e estão relacionados ao contato das camadas visceral e parietal do pericárdio, envolvidas por um processo inflamatório.

PAZIN FILHO A; SCHMIDT A \& MACIEL BC. Cardiac auscultation: Physiological and physiopathological mechanisms. Medicina, Ribeirão Preto, 37: 208-226, july/dec. 2004

ABSTRACT: The physiologic and physiopathological mechanisms of normal and abnormal heart sounds are reviewed, including their implications for bedside cardiac auscultation.

UNITERMS: Heart Auscultation. Heart Sounds.

\section{BIBLIOGRAFIA RECOMENDADA}

1 - CONSTANT J. Bedside cardiology. $2^{\text {th }}$. ed. Little Brown Boston, 1976.

2 - MACIEL BC. Cardiac auscultation: Physiological and physiopathological mechanisms. Medicina, Ribeirão Preto, 27: 126-144, 1994
3 - PERLOFF JK. Cardiac auscultation. Dis Mon 26: 1-46, 1980.

4 - PERLOFFJK. Heart sounds and murmurs: Physiological mechanisms. In: BRAUNWALD E. Heart disease. W.B.Saunders, Philadelphia, p. 43-47, 1992.

5 - TAVEL, ME. Clinical phonocardiography and external pulse recordng. $3^{\text {th }}$ Year Book Medical, Chicago, 1978. 